CASTRO, L. S. de; CARNEIRO, R. A. F. CONSEQUÊNCIAS do arcabouço regulatório do biodiesel brasileiro para as usinas produtoras: uma análise da situação da Bahia

\title{
CONSEQUÊNCIAS DO ARCABOUÇO REGULATÓRIO DO BIODIESEL BRASILEIRO PARA AS USINAS PRODUTORAS: UMA ANÁLISE DA SITUAÇÃO DA BAHIA
}

\author{
Luciano Sousa de Castro ${ }^{1}$ \\ Roberto Antônio Fortuna Carneiro ${ }^{2}$
}

\begin{abstract}
RESUMO
O presente artigo aborda as consequências que o arcabouço regulatório do Programa Nacional de Produção e Uso do Biodiesel (PNPB) tem para formação de uma cadeia de valor na produção de biodiesel no estado da Bahia. Para isso foi realizada uma revisão acerca dos principais instrumentos regulatórios e de fomento ao biodiesel no país, utilizando uma metodologia de pesquisa fundamentada em revisão de literatura, pesquisa de campo e aplicação de questionário em usina de biodiesel e cooperativas agrícolas localizada no estado da Bahia para levantamento de dados primários. Essa pesquisa tem relevância social, pois aborda um tema que é muito debatido mundialmente, que é a criação de fontes renováveis de energia. Neste estudo é analisada a relação entre o arcabouço regulatório do biodiesel e seus impactos na formação da cadeia de valor do produto. Foram abordadas ainda as dificuldades enfrentadas pelo estado da Bahia na formação e consolidação dos agentes participantes da produção do biodiesel. Foi percebido no estudo que existem grandes dificuldades para garantir o abastecimento das usinas localizadas no estado da Bahia com as oleaginosas geradas na própria região, devido a problemas relacionados à cultura dos cooperativados, dificuldade de gestão, deficiência técnica e de infraestrutura de transporte. Sendo assim, surge a necessidade de uma maior reflexão e debates acerca das políticas de regulação estarem ou não atendendo o estado da Bahia na estruturação de um mercado de biodiesel de forma sustentável.
\end{abstract}

Palavras-chave: Biodiesel. Organização da produção. Regulação. Cadeia de valor. Programa nacional de produção e uso do biodiesel.

\section{INTRODUÇÃO}

No atual cenário mundial, no qual os recursos naturais tornam-se, a cada dia, mais escassos, e as questões relacionadas à preservação ambiental estão mais presentes e inseridas

\footnotetext{
${ }^{1}$ Mestre em Tecnologias Aplicáveis à Bioenergia pela Faculdade de Tecnologia e Ciências de Salvador (FTC). Especialista em Gestão de Pessoas e Bacharel em Administração pela Faculdade da Cidade de Salvador (FCS). Coordenador e professor do curso de Bacharelado em administração da FTC. E-mail: lucianocastroadm@gmail.com.

2 Mestre em Administração pela Universidade Federal da Bahia (UFBA). Graduado em Geografia pela Universidade Católica do Salvador (UCSAL). Professor Titular do Mestrado Profissional em Bioenergia e da Pós Graduação em Gestão Ambiental da Faculdade de Tecnologia e Ciências de Salvador. Diretor de Planejamento da Secretaria de Planejamento do Estado da Bahia. E-mail: rfortuna.c@ gmail.com.
} 
CASTRO, L. S. de; CARNEIRO, R. A. F. CONSEQUÊNCIAS do arcabouço regulatório do biodiesel brasileiro para as usinas produtoras: uma análise da situação da Bahia

no contexto social e econômico, expandir e diversificar as fontes renováveis de energia é uma condição indispensável para auxiliar o crescimento em bases mais sustentáveis. Nesse contexto, a produção de biocombustíveis (designadamente o etanol e o biodiesel) desponta como uma alternativa ao uso dos combustíveis fósseis, constituindo uma realidade no quadro energético mundial e, também, no panorama brasileiro (BRAGA, C.; BRAGA, L., 2012).

Segundo César (2009), as expectativas de esgotamento de petróleo previstas para os próximos 50 anos, os aumentos nos custos de exploração, questões geopolíticas e os efeitos nocivos das mudanças no clima são indicativos da necessidade de redução da dependência gradual da energia fóssil.

Diante desse cenário, o biodiesel surge como fonte de energia com potencial de substituir o diesel de petróleo, promover a inclusão social por meio de inserção da agricultura familiar e preservar o meio ambiente graças à produção em escala de uma fonte energética mais renovável. O biodiesel é uma fonte energética de suma importância para o Brasil, pois além de diversificar a matriz brasileira de energia ainda possui um caráter ambientalmente sustentável. Segundo Braga, C. e Braga, L. (2012), o caráter renovável está apoiado no fato de serem suas matérias primas, na sua maior parte, oriundas de práticas agrícolas, ou seja, de fontes renováveis, ao contrário dos derivados de petróleo.

Para estruturar a formação de uma cadeia produtiva de biodiesel no país foram desenvolvidas políticas de regulação estruturadas com base nas diretrizes estabelecidas no Programa Nacional de Produção e Uso do Biodiesel (PNPB). Este programa foi lançado pelo Governo Federal no ano 2004 e, segundo Cunha (2010), visou promover o desenvolvimento rural, principalmente da agricultura familiar, o crescimento da agroindústria produtora de biodiesel e impactar positivamente o meio ambiente.

Para Paulillo, Mello e Vian (2006), ao visar inserir a agricultura familiar num contexto de desenvolvimento econômico e social, o Governo Federal criou um modelo de organização e integração da produção de oleaginosas voltada para a produção de biodiesel nas usinas, obrigadas estas a comprar matérias primas das cooperativas de agricultores familiares. Entretanto, vários problemas foram gerados com tal obrigatoriedade, sendo o mais marcante a dificuldade enfrentada pelas usinas de biodiesel para adquirir matérias prima em qualidade e quantidade necessária para suprir sua demanda.

A obrigatoriedade de aquisição de matérias primas dos agricultores familiares para a obtenção de benefícios fiscais e creditícios, a partir de um modelo contratual determinado 
CASTRO, L. S. de; CARNEIRO, R. A. F. CONSEQUÊNCIAS do arcabouço regulatório do biodiesel brasileiro para as usinas produtoras: uma análise da situação da Bahia

pelo governo federal, com regras de negociação para compra e venda e formação de preços para aquisição da safra agrícola das cooperativas vinculadas ao PNPB mediadas pelo governo, associada à ausência de mecanismos coercitivos que impeçam as quebras de contratos de fornecimento, está ocasionando uma volatilidade na oferta de matérias primas para a produção de biodiesel e um risco à sustentabilidade econômica e financeira das empresas no estado. Diante disso, o estudo busca apresentar de forma clara uma análise acerca da importância do arcabouço regulatório do biodiesel brasileiro para criação da cadeia de valor.

A metodologia escolhida para a pesquisa utilizou informações tanto qualitativas quanto quantitativas, pois além de fundamentar a pesquisa com dados o tema exigiu a analise de variáveis situacionais relacionados à cadeia do biodiesel. Serão apresentados dados primários coletados por meio questionário e entrevistas semiestruturadas realizadas em sete das treze cooperativas agrícolas do estado classificadas como "ativas" pelo Ministério do Desenvolvimento Agrário (MDA) e na usina de biodiesel da Petrobrás Biocombustíveis (PBio) localizada no município de Candeias. Foram coletados ainda dados secundários através de pesquisa bibliográfica em literatura especializada sobre o tema estudado. Para levantamento do arcabouço regulatório referente ao PNPB e coleta de dados estatísticos se fez uso de órgãos que gozam de credibilidade nacional e possuem competência técnica para a prestação dessas informações como, por exemplo, o Ministério do Desenvolvimento Agrário (MDA), Ministério de Minas e Energia (MME), Agência Nacional de Petróleo, Gás Natural e Biocombustíveis (ANP), Secretaria de Infraestrutura do Estado da Bahia (SEINFRA), dentre outros.

O método de pesquisa inicial foi de natureza exploratória, para que houvesse familiarização com a problemática envolvida. Posteriormente foi aplicada uma pesquisa descritiva, por meio de questionários semiestruturados para buscar junto aos órgãos e empresas relacionadas à cadeia de biodiesel informações relevantes sobre o seu funcionamento. Segundo Gil (2010), a pesquisa exploratória tende a ser mais flexível, pois considera os mais variados aspectos relativos ao fenômeno estudado. $\mathrm{O}$ questionário aplicado fez uso de perguntas abertas e fechadas para possibilitar o entendimento acerca de como a problemática era entendida, bem como saber quais dificuldades cada setor enfrentava.

\section{A CADEIA DE VAlOR E SUA RELAÇÃO COM AS POLÍticas REGULATÓRIAS E DE FOMENTO PARA A PRODUÇÃo DE BIODIESEL NO PAÍS}


CASTRO, L. S. de; CARNEIRO, R. A. F. CONSEQUÊNCIAS do arcabouço regulatório do biodiesel brasileiro para as usinas produtoras: uma análise da situação da Bahia

Os modelos de organização da produção são de fundamental importância para a cadeia produtiva de um determinado setor, pois são eles que garantirão uma produção competitiva e em larga escala. Segundo Porter (1989), uma cadeia de valor é composta por todos os agentes participantes da produção e comercialização do produto, ou seja, nela estão inseridos os produtores da matéria-prima, os fornecedores de insumos, os clientes, a logística, a infraestrutura energética e de telecomunicações, as políticas econômicas e de regulação envolvidas, o acesso a financiamento, a concorrência e a relação com a sociedade envolvida.

No que concerne ao biodiesel brasileiro, sua cadeia de valor de um ponto de vista sintético está dividida em agricultura (familiar e empresarial), esmagadoras, usinas de biodiesel, refinarias, distribuidoras e postos de combustíveis. Importante observar que todos os agentes relacionados são de natureza privada e que diretamente estão sendo influenciados ou regulados pelo Governo Federal por meio do PNPB.

Ainda segundo Porter (1989), a cadeia de valor é a reunião de atividades que são executadas para projetar, produzir, comercializar, entregar e sustentar um produto. Essas peças que compõem a cadeia de valor visam gerar para o biodiesel uma série de vantagens econômicas, financeiras, tecnológicas e sociais.

A cadeia de valor está diretamente ligada à cadeia produtiva. Esta segunda, no caso do biodiesel, é composta também pelos fornecedores de sementes e adubos, pelo mercado de máquinas e implementos agrícolas, pelas universidades que pesquisam e desenvolvem novas tecnologias, por empresas de logística que atuam na movimentação da matéria prima, pelos fornecedores de produtores químicos necessários para transformação do biodiesel. Logo, a cadeia produtiva trabalha ao lado da cadeia de valor fornecendo produtos e serviços necessários a manutenção de suas atividades. Essa cadeia produtiva, segundo César, Bonfim e Batalha (2012), foi organizada pelo PNPB por meio do marco regulatório do programa, que definiu as linhas de financiamento, a estruturação da base tecnológica e o Selo Combustível Social, mecanismos que têm determinado o desenvolvimento dessa cadeia de valor para o biodiesel no país.

O Selo Combustível Social foi um mecanismo utilizado pelo Governo Federal com intuito de incentivar as usinas de biodiesel a adquirirem matéria prima oriunda da agricultura familiar. Sendo assim, usinas de biodiesel que adquirissem as matérias prima de cooperativas agrícolas vinculadas ao PNPB recebiam facilidades na concessão de crédito e tinham ainda 
CASTRO, L. S. de; CARNEIRO, R. A. F. CONSEQUÊNCIAS do arcabouço regulatório do biodiesel brasileiro para as usinas produtoras: uma análise da situação da Bahia

benefícios fiscais diferenciados. Para Alvarenga e Young (2013) afirmam que o Selo Combustível Social foi criado com intuito de promover inclusão social da agricultura familiar Já para Martins (2013), um dos mecanismos de inclusão marcante foi à criação do Selo Combustível Social, uma vez que concede redução de alíquotas de impostos (PIS/PASEP; COFINS; IPI) para produtores de biodiesel que adquirirem matéria-prima da agricultura familiar. Logo, possui forte condição de ajudar na formação da cadeia de valor.

Para Porter (1989), a cadeia de valor é um instrumento básico para diagnosticar a vantagem competitiva e descobrir maneiras de criá-la e sustentá-la. Ela oferece uma forma sistemática de organização de todos os agentes que compõem um produto e que são indispensáveis para seu crescimento em escala. O sistema de organização de produção de um setor produtivo específico precisa sempre estar associado à sua cadeia de valor, pois suas especificidades têm impactos diretos em diversos fatores da produção, como por exemplo, na definição de preço, prazo de entrega, escoamento do produto, etc. É importante entender que gargalos ou problemas na cadeia de valor de um produto, no caso específico desse estudo, o biodiesel poderá comprometer a sua produção, qualidade e preço, ou seja, a própria sustentabilidade do negócio.

É importante entender que o mercado de biodiesel precisa estar embasado numa relação de respeito às regras estabelecidas em contrato com seus agentes envolvidos. Seu ciclo produtivo precisa oferecer tranquilidade no desenvolvimento de sua produção. Esse contexto somente pode acontecer se houver um modelo adequado e eficiente de organização da produção. Segundo Ferreira e Carneiro (2013), para que a cadeia produtiva aconteça de forma eficiente é necessário compreender como ela está formada e estruturada no segmento inserido. Tal compreensão facilita a análise de situações que possam vir a se tornar problemas ou dificuldade na sua existência, facilitando o uso de mecanismos de correção.

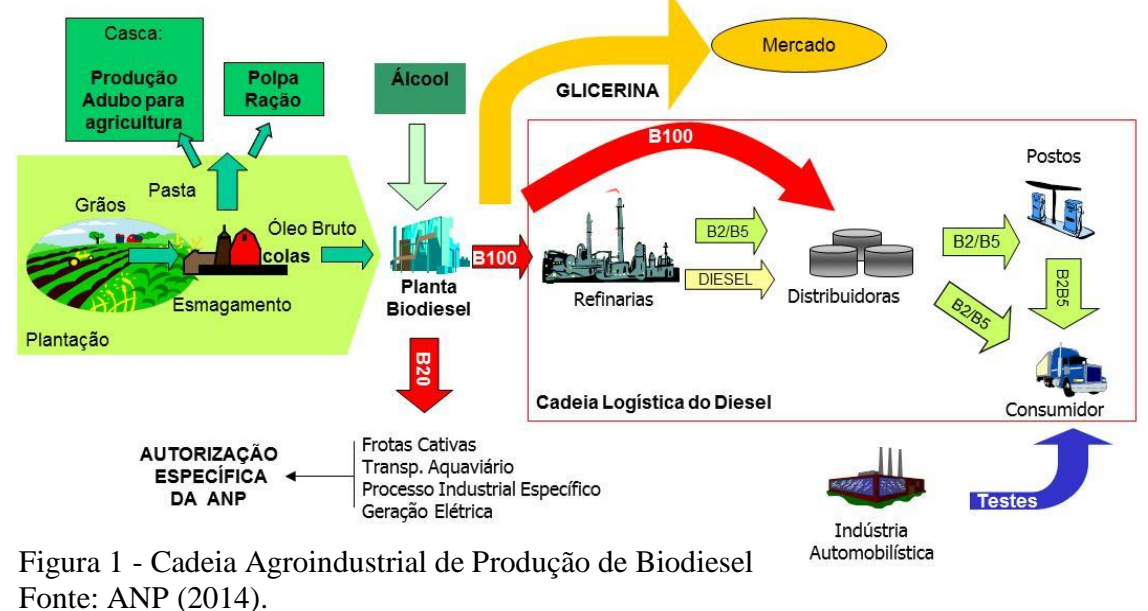


CASTRO, L. S. de; CARNEIRO, R. A. F. CONSEQUÊNCIAS do arcabouço regulatório do biodiesel brasileiro para as usinas produtoras: uma análise da situação da Bahia

A Figura 1, apresentada acima, ilustra a cadeia agroindustrial de produção do biodiesel, com todos os seus agentes participantes. Ela compreende todas as etapas do processo, iniciando com a agricultura (familiar ou empresarial), passando pelo esmagamento das oleaginosas, usinas, refinarias, distribuidoras, postos de combustível, até chegar ao consumidor final. Além disso, esta cadeia tanto recebe como oferece produtos necessários para outros mercados gerando uma interação entre vários setores cuja resposta é benéfica para a economia. As questões da cadeia de valor possuem ligação direta com o arcabouço regulatório, responsável por estabelecer políticas públicas, financiamentos e fiscalização de todo o processo que envolve o produto, dentre outras ações.

No que concerne ao biodiesel, todo o arcabouço regulatório está alicerçado no PNPB, que foi concebida visando garantir atender a questões mercadológicas, sociais e ambientais (BRASIL, 2014). Este arcabouço envolve todo um conjunto de ações, decisões e regras destinadas a buscar soluções para algum tipo de problema ou situação que seja de relevância para a sociedade.

O marco regulatório é formado por atos legais que tratam dos percentuais de mistura do biodiesel ao diesel, da forma de utilização e do regime tributário, que considera a diferenciação das alíquotas com base na região de plantio, nas oleaginosas e na categoria de produção - agronegócio ou agricultura familiar (BRASIL, 2004).

As políticas públicas normalmente são formuladas por meio de demandas apresentadas pela sociedade aos governos públicos. Para isso é necessário que os cidadãos interessados se organizem em grupos denominados de Sociedade Civil Organizada (SCO). Cada SCO atua na busca de seus interesses e pressiona o governo para que sejam criadas políticas publicam que atendam a sua necessidade. A criação de políticas públicas e sua execução é basicamente trabalhada sob o ponto de vista de dois atores: governo e sociedade. Ambos precisam atuar na discussão de todos os fatores que definirão as regras para o segmento tratado, formulando agenda para seleção de prioridades, formulação das próprias políticas e suas prioridades, escolhendo as ações a serem adotadas e executando-as e por fim avaliando o resultado de cada ação. Em relação a políticas para o mercado de biodiesel, podemos visualizar as decisões governamentais que são realizadas para a sua agricultura, indústria, pesquisa de desenvolvimento de tecnologia, regulação e financiamento.

A política de regulação aplicada à produção de biodiesel deve proporcionar eficiência alocativa dos insumos do produto, assegurando sua diversificação, redução dos 
CASTRO, L. S. de; CARNEIRO, R. A. F. CONSEQUÊNCIAS do arcabouço regulatório do biodiesel brasileiro para as usinas produtoras: uma análise da situação da Bahia

custos de produção, desenvolvimento tecnológico, social e científico. Tais ações perpassam por investimentos controlados pelo Estado que objetivam o desenvolvimento da indústria do biodiesel.

Segundo Barros (1997 apud PIZAIA et al., 2004), a regulação é o conjunto de leis e controles administrativos que se originam do governo e afetam o funcionamento dos mercados, ao interferir na eficiência interna e alocativa da economia. Já para Peci (2007), os objetivos de uma política reguladora são a defesa da concorrência e do usuário dos serviços públicos. A regulação visa manter o chamado equilíbrio econômico-financeiro, não permitindo que seus interessados sejam lesados.

As políticas públicas para o biodiesel visam fomentar ainda a participação de empresas privadas no mercado por meio de incentivos fiscais e acesso a financiamento em melhores condições que as aplicadas pelo mercado. Para isso, o governo faz uso de bancos de créditos que disponibilizam financiamento para ações destinadas ao crescimento do biodiesel. De acordo com Souza (2006), pode-se afirmar que as políticas públicas buscam colocar o governo em ação e, quando necessário, propor mudanças no rumo ou curso dessas ações. Logo, cabe também ao Governo Federal analisar se a regulação utilizada para o biodiesel precisa ser reformulada visando o seu aperfeiçoamento. Para isso é necessário acompanhar todos os indicadores relacionados à saúde da cadeia produtiva do biodiesel, analisando em quais etapas estão acontecendo problemas, para que se possa realizar as devidas correções e ajustes no programa.

De acordo com Martins (2013), o PNPB institucionalizou a base normativa para produção e comercialização de biodiesel no Brasil, criando o modelo tributário para este novo mercado e intensificando a participação da agricultura familiar nesse contexto.

Logo, sua atuação abrange de forma ampla toda a cadeia de produção do biodiesel, regulando a atividade de produção, delimitando as características técnicas do combustível, criando as regras de financiamento para os agentes participantes da esfera produtiva, definindo a estrutura de comercialização e o respectivo modelo de tributação que deve ser aplicado.

Segundo Quintella et al. (2009) para gerar valor a cadeia do biodiesel precisa estar alicerçada numa política de Estado envolvendo aspectos tanto econômico quanto financeiros, a exemplo de incentivos fiscais e linhas de financiamento mais vantajosas, além de aspectos legais como normas e especificações. 
CASTRO, L. S. de; CARNEIRO, R. A. F. CONSEQUÊNCIAS do arcabouço regulatório do biodiesel brasileiro para as usinas produtoras: uma análise da situação da Bahia

A forma como um país estabelece seu marco regulatório acerca de um produto ou serviço caracteriza de forma direta a constituição de toda cadeia de valor que o envolve, pois na legislação aplicada ao segmento estão às regras para o seu financiamento, tributação, parceria entre os agentes envolvidos, questões relacionadas à participação do Estado e investimentos em infraestrutura de uma forma geral.

A principal lei do arcabouço regulatório do biodiesel no país é a Lei $\mathrm{n}^{\mathrm{o}}$ 11.097, publicada no dia 13 de janeiro de 2005 no Diário Oficial da União, que dispõe sobre a introdução do biodiesel na matriz energética brasileira e estabelece a Agência Nacional do Petróleo, Gás Natural e Biocombustível (ANP) como órgão responsável por promover a regulação, contratação e fiscalização de toda atividade econômica dos integrantes da indústria do petróleo, gás natural e biocombustíveis.

\section{O REFLEXO DAS POLÍTICAS DE REGULAÇÃO NO ESTADO DA BAHIA}

Apesar de ser a principal economia do Nordeste, o estado da Bahia ainda não consegue acompanhar a produção de biodiesel de outras regiões, a exemplo de Sudeste e Centro-Oeste. Tal situação pode estar acontecendo por uma série de questões que vão desde a infraestrutura de estradas e transporte, investimento necessário do setor privado, chegando à falta de condições adequadas da agricultura familiar do estado de responder a demanda crescente pelo biodiesel. Porém, é importante observar que a Bahia possui características próprias e que precisam ser levadas em consideração pelos órgãos formuladores da regulação.

O país criou um arcabouço que não analisou independentemente cada região para adaptar suas limitações ao mercado. Consequentemente, existem distorções regionais grandes no que concerne a produção da Bahia, comparada a outras regiões, principalmente o Centrooeste. $\mathrm{O}$ estado tem sofrido com a dificuldade que a agricultura familiar tem de atender a demanda das usinas por matérias primas e por conta disso sua cadeia de valor tem se mostrado fragilizada. As usinas de biodiesel no estado têm fechado, sendo que no momento apenas duas estão em funcionamento, a Petrobras Biocombustíveis (PBIO) localizada em Candeias e a Oleoplan localizada em Iraquara

Importante salientar que existem algumas diferenças entre a forma como acontece à agricultura da Bahia e o modelo utilizado em outras regiões. Historicamente a região CentroOeste sempre se caracterizou por uma agricultura forte nos estados de Mato Grosso, Mato 
CASTRO, L. S. de; CARNEIRO, R. A. F. CONSEQUÊNCIAS do arcabouço regulatório do biodiesel brasileiro para as usinas produtoras: uma análise da situação da Bahia

Grosso do Sul e Goiás. Seu cultivo agrícola era basicamente voltado para a produção de soja, direcionada para o mercado de alimentos. Na região toda a cadeia de valor que envolve essa produção tem uma base forte e bem instalada. Com a criação do PNPB os grandes agricultores da região, que já possuíam experiência empresarial no segmento, perceberam que teriam uma oportunidade de negócio que poderia aumentar a produção de soja, uma vez que deixariam de fornecer apenas como alimento e passariam a utilizar também para produção de biodiesel. Nesse contexto, a soja passa a fazer parte de um novo segmento de mercado.

Essa facilidade gerada pela cultura regional oriunda da agricultura empresarial tornou a integração entre agricultura, esmagadoras, transportadoras e usinas de biodiesel muito mais eficiente, uma vez que não houve necessidade de grandes adaptações ao processo. Vale deixar claro que como o Brasil utiliza em sua grande maioria a soja como matéria prima para o biodiesel, à região Centro-Oeste se favoreceu muito mais com o PNPB quando comparada com a região Nordeste e mais especificamente a Bahia. Essa dificuldade da Bahia em criar uma cadeia de produtiva forte é um ponto de dificuldade no que se refere à questão de desenvolvimento da produção de biodiesel local. Talvez o estado ainda não tenha conseguido diagnosticar e corrigir corretamente os entraves ao crescimento exponencial do produto. Para Silva (2015), a justificativa de analisar as cadeias produtivas de biodiesel na Bahia está atrelada à situação em que se encontra o setor agrícola e industrial do biodiesel, o que implica na necessidade de pesquisar sobre o nível de competitividade.

Ao fazer essa afirmação este autor mostra preocupação com a condição da Bahia no mercado de biodiesel. De fato existe necessidade de análise da cadeia produtiva de biodiesel e sua competitividade, mas tal análise precisa abordar questões importantes sobre como foi inserida a agricultura familiar por meio do PNPB e suas limitações nas condições sociais do estado.

Culturalmente os agricultores familiares baianos estão acostumados a negociar diretamente com um comprador recebendo o valor pela produção no momento da venda. Ainda é muito frágil a cultura de associação e de relacionamento com os compradores por meio de contratos com direitos e obrigações a serem atendidas pelas partes. Obrigações essas que por limitações culturais, financeiras, de infraestrutura e de gestão muitas vezes não podem ser atendidas pelo agricultor familiar. A maneira como foi estabelecida a regulação dos contratos entre usinas e agricultura familiar por intermédio das cooperativas talvez seja então 
CASTRO, L. S. de; CARNEIRO, R. A. F. CONSEQUÊNCIAS do arcabouço regulatório do biodiesel brasileiro para as usinas produtoras: uma análise da situação da Bahia

um agravante para a produção de biodiesel no estado, pois a agricultura familiar local não tem atendido adequadamente a demanda das usinas por oleaginosas.

Apesar das dificuldades, a Bahia tem registrado crescimento na produção do óleo. As informações a seguir são da Secretária de Infraestrutura da Bahia - SEINFRA e estão apresentados em toneladas equivalentes de petróleo (tep). De acordo com a SEINFRA, no ano de 2007 o volume de óleo vegetal produzido foi de 61 ( $10^{3}$ tep) tendo crescido em 2013 para $165\left(10^{3}\right.$ tep). Importante registrar que o ano de maior produção até o momento foi 2012, com 196 (10³ tep) (BAHIA, 2014).

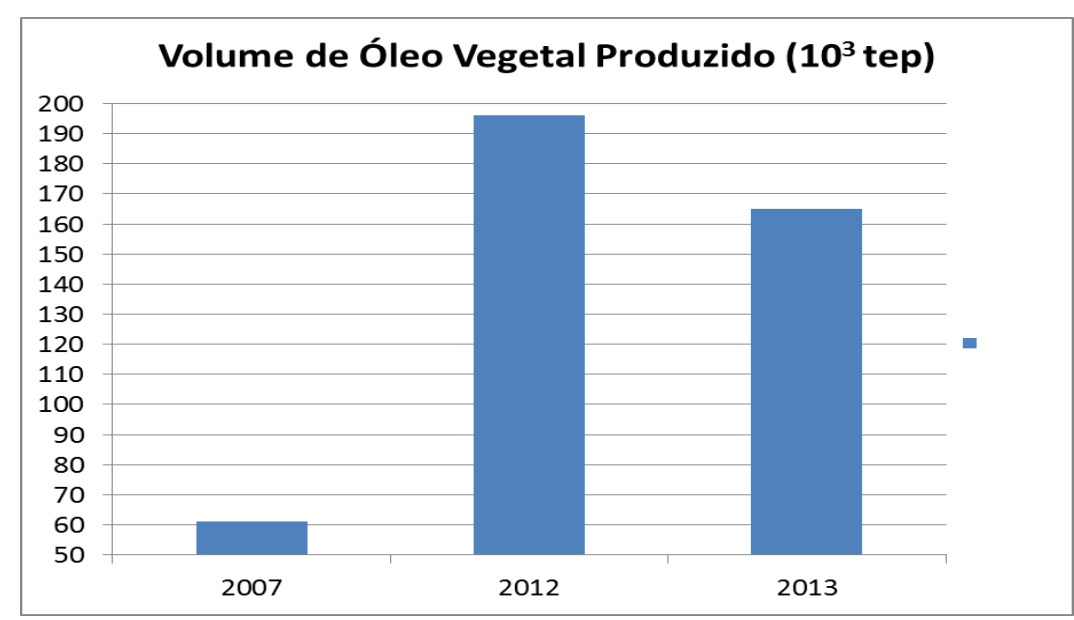

Gráfico 1 - Volume de óleo vegetal produzido no estado da Bahia

Fonte: Elaborado pelos autores com base nos dados da SEINFRA (2015).

Segundo dados do Ministério de Minas e Energia - MME (2014), a Bahia tem apenas 6,8\% do total de biodiesel produzido no Brasil, sendo que o Rio Grande do Sul, região que utiliza a soja para produção de biodiesel, inclusive por agricultores familiares, é o maior produtor do país com 28,7\% de participação. Mesmo tendo um potencial grande para produzir soja, algodão, girassol, sebo bovino e palma o estado ainda tem uma parcela pequena do mercado. Com um percentual tão baixo de contribuição no nível de Brasil é fácil questionar até que ponto o marco regulatório está funcionando para a Bahia.

O principal ponto a ser esclarecido nessa pesquisa é mostrar a importância do arcabouço regulatório do biodiesel e se o mesmo está conseguindo fomentar a criação de uma cadeia de valor no estado da Bahia. Diante de tal problemática foi realizada aplicação de questionário em cooperativas agrícolas habilitadas pelo MDA e apresentadas em quadro abaixo: 
CASTRO, L. S. de; CARNEIRO, R. A. F. CONSEQUÊNCIAS do arcabouço regulatório do biodiesel brasileiro para as usinas produtoras: uma análise da situação da Bahia

\begin{tabular}{|c|c|c|c|c|c|}
\hline COOPERATIVA & MUNICÍPIO & $\begin{array}{c}\text { RENDA } \\
\text { FAMILIAR }\end{array}$ & $\begin{array}{c}\text { NÚMERO DE } \\
\text { COOPERATIVADOS }\end{array}$ & $\begin{array}{c}\text { TEMPO DE } \\
\text { FUNCIONAMENTO }\end{array}$ & $\begin{array}{c}\text { OLEAGINOSA } \\
\text { CULTIVADA }\end{array}$ \\
\hline COOMTRATA & NAZARÉ & RS 900,00 & 278 & 15 ANOS & DENDE \\
\hline COOPAGRIL & MORRÓ DO CHAPÉU & RS 300,00 & 921 & 5 ANOS & MAMONA \\
\hline COAGRI & IBITITÁ & RS 600,00 & 184 & 13 ANOS & MAMONA \\
\hline COOPAF & MORRÓ DO CHAPÉU & R\$ 900,00 & 5.000 & 10 ANOS & MAMONA \\
\hline COOPERGRÃOS & IRECEे & RS 800,00 & 150 & 5 ANOS & MAMONA \\
\hline COOFAVA & VALENÇA & RS $1.000,00$ & 930 & 7 ANOS & côco \\
\hline COPIRECÊ & IRECE & RS 788,00 & 553 & 45 ANOS & MAMONA \\
\hline
\end{tabular}

Quadro 1 - Cooperativas agrícolas vinculadas ao PNPB no estado da Bahia e participantes da pesquisa Fonte: Elaborado pelos autores com base na aplicação de questionário (2015).

A pesquisa foi realizada em sete cooperativas agrícolas de cinco municípios diferentes, sendo que três delas (COOMTRATA, COAGRI e COPIRECÊ) possuem mais tempo de existência que o PNPB e uma (COOPAF) o mesmo tempo de existência do Programa, que é de pouco mais de 10 anos. A mais antiga das cooperativas pesquisadas foi a COPIRECÊ, que tem 45 anos de existência e quinhentos e cinquenta e três associados. A maior delas é a COOPAF, localizada no município de Morro do Chapéu com cinco mil associados ativos e dez anos de existência, ou seja, a mesma idade do PNPB. A menor é a COOPERGRÃOS com cento e cinquenta associados e cinco anos de criação. O resultado dessa pesquisa evidenciou a existência de problemas que dificultam a formação de uma cadeia de valor para o biodiesel no Estado da Bahia.

Ao serem questionadas, por exemplo, sobre a oleaginosa utilizada e negociada com o mercado de biodiesel, das sete cooperativas pesquisadas, cinco utilizam a mamona como matéria prima negociada com as usinas e apenas duas responderam "outras", apontando o dendê e o côco como oleaginosa produzida pelos seus cooperativados. Ou seja, mesmo não sendo uma oleaginosa adequada para transformação em biodiesel por limitações técnicas definidas pela própria ANP (viscosidade e densidade) a mamona contínua sendo adquirida pelas usinas, muito provavelmente por conta dos benefícios gerados pelo Selo Combustível Social.

Vale registrar que culturalmente a mamona é muito cultivada pela agricultura baiana, que vende sua produção para indústria ricinoquímica. Essa oleaginosa possui grande valor de mercado para o segmento e por conta disso as cooperativas permanecem fazendo a manutenção do seu cultivo. Durante pesquisa de campo foi relatado por cooperativados que a manutenção da cultura da mamona acontece em virtude dos mesmos ainda não se sentirem 
CASTRO, L. S. de; CARNEIRO, R. A. F. CONSEQUÊNCIAS do arcabouço regulatório do biodiesel brasileiro para as usinas produtoras: uma análise da situação da Bahia

seguros com o PNPB. Eles afirmam que na prática ainda não foi percebida muita mudança na sua situação econômica e consequentemente social.

Isso é um indicador que mostra que de fato a Bahia possui uma baixa oferta de oleaginosa oriunda da agricultura familiar e destinada de fato à produção do biodiesel, o que elucida um dos questionamentos da pesquisa acerca do fato da sustentabilidade das usinas no estado estar comprometida pela baixa oferta de matéria prima pelas cooperativas agrícolas vinculadas ao PNPB. Evidencia-se que ao produzirem matéria prima e destiná-la, mesmo que parcialmente, para outros mercados a manutenção do volume necessário para as usinas de biodiesel pode ficar comprometida.

O Selo Combustível Social é um mecanismo criado pelo governo federal que garante benefícios fiscais e creditícios para as usinas de biodiesel que adquirem matéria prima oriunda da agricultura familiar. Além disso, ainda obriga as usinas produtoras de biodiesel a oferecerem garantias de compra da safra, garantir o transporte da mesma, fazerem prestação de assistência técnica e distribuição de sementes às cooperativas de agricultores familiares vinculadas ao PNPB.

Com relação à renda média das cooperativas com o mercado de biodiesel, esta é de $\mathrm{R} \$ 755,43$ (setecentos e cinquenta e cinco reais), sendo que a maior faixa de renda foi de $\mathrm{R} \$$ 1.000,00 (mil reais) na COOFAVA e a menor faixa de renda ficou em $\mathrm{R} \$ 300,00$ (trezentos reais) na COOPAGRIL. Logo, analisando a questão da mudança do patamar social dos cooperativados pode-se deduzir que o PNPB, na Bahia, não é um grande agente de transformação social, uma vez que a media de renda das famílias não se distancia do valor do salário mínimo que é de $\mathrm{R} \$ 788,00$ (setecentos e oitenta e oito reais).

Quanto ao questionamento acerca do destino principal da produção das cooperativas; quatro delas responderam que destinam sua produção para o mercado de biodiesel, duas destinam ao mercado de alimentos e uma para a indústria ricinoquímica. $\mathrm{O}$ fato de duas delas apontarem "outros" à frente do mercado de biodiesel abre um espaço para reflexão, pois mostra que as cooperativas têm buscado outros mercados para garantir a venda da sua produção. Pelo fato da maioria delas estar produzindo apenas uma cultura não está sendo disseminado outro desejo do PNPB que é o cultivo de policulturas agrícolas.

Outra constatação interessante foi a de que está havendo uma quebra de contrato por parte das usinas de biodiesel em relação à exigência do MDA para que seja feita prestação de assistência técnica e distribuição de sementes de qualidade para as cooperativas. Das sete 
CASTRO, L. S. de; CARNEIRO, R. A. F. CONSEQUÊNCIAS do arcabouço regulatório do biodiesel brasileiro para as usinas produtoras: uma análise da situação da Bahia

cooperativas pesquisadas apenas duas afirmaram ter recebido regularmente o serviço de assistência técnica e distribuição de sementes, uma afirmou que recebe esporadicamente e quatro informaram não ter recebido esse tipo de apoio. Não foi registrado durante a pesquisa qual o tipo de semente recebida pelas cooperativas. Como as cooperativas são muito dependentes do apoio das empresas, essa situação prejudica a produção de oleaginosas, uma vez que não existe uma orientação adequada e também acesso a sementes em número e qualidade necessária para aumentar a produtividade.

Importante destacar que no caso da Bahia, a distribuição de sementes, quando realizada pelas usinas produtoras de biodiesel, aparentemente não está levando em consideração o tipo de oleaginosa que será plantada. Ou seja, as usinas estão distribuindo sementes de oleaginosas inadequadas à produção de biodiesel muito provavelmente para apenas cumprir contratado e usufruir dos benefícios disponibilizados pelo governo. Tal situação se configura como um erro, pois corrobora com a baixa oferta de matéria prima oriunda da agricultura familiar.

No que se refere à relação contratual das cooperativas agrícolas pesquisadas e as usinas de biodiesel foi perguntado como elas avaliam essa relação. Quatro delas responderam considerar satisfatória e três delas entendem que a relação é insatisfatória. Registra-se que nas cooperativas que afirmaram insatisfação com os contratos constam as duas que afirmaram vender para outros mercados. As cooperativas que responderam que sua relação com as usinas de biodiesel é insatisfatória apontaram com motivos para isso a falta de regularidade na aquisição da oleaginosa e a falta de compromisso com as famílias de cooperativados e interesse apenas na redução fiscal garantida pelo Selo Combustível Social.

O preço estabelecido nos contratos entre as cooperativas agrícolas e as usinas de biodiesel foi abordado no questionário e mostrou que cinco cooperativas entendem que o valor celebrado entre as partes remunera adequadamente as famílias de agricultores. Uma das cooperativas considerou o preço inadequado e outra não respondeu ao questionamento. $\mathrm{O}$ dado sugere que a dificuldade das cooperativas em se firmarem no mercado de biodiesel não está na definição do preço negociado com as usinas.

Foi questionado ainda se as cooperativas estavam recebendo propostas de compra da sua produção por empresas fora do mercado do biodiesel. Duas delas afirmaram ter recebido propostas para os mercados de alimentos e indústria ricinoquímica. Posteriormente foi perguntado se no caso de receberem propostas de outros mercados, com melhores condições 
CASTRO, L. S. de; CARNEIRO, R. A. F. CONSEQUÊNCIAS do arcabouço regulatório do biodiesel brasileiro para as usinas produtoras: uma análise da situação da Bahia

financeiras, haveria negociação para aquisição da oleaginosa mesmo havendo contrato celebrado junto às usinas de biodiesel. Para essa situação, cinco cooperativas agrícolas informaram que não aceitariam a proposta, uma vez que estavam comprometidas por contrato com as usinas de biodiesel.

Importante observar que no caso da Bahia existem duas questões complicadas no que concerne ao abastecimento das usinas pelas cooperativas agrícolas. A primeira é que culturalmente a agricultura familiar baiana não aderiu completamente ao PNPB e contínua fazendo plantio de oleaginosa que não possuem condições adequadas a produção do biodiesel, a exemplo da mamona. A segunda questão está no fato de que mesmo tendo assinado contrato com as usinas, ao sofrerem assédio de outros mercados, algumas cooperativas não têm qualquer restrição à venda. Isso evidencia que as regras de mercado precisam ser revistas para fortalecer a relação entre usinas de biodiesel e cooperativas agrícolas, visando garantir aumento nos insumos necessários a produção do biodiesel.

No que concerne à pesquisa de campo realizada na cidade de Nazaré, foi percebida uma forte insegurança por parte das famílias que integram a cooperativa agrícola visitada, por conta da demora no processo de crescimento da renda dos cooperativados. Foi percebido que uma série de fatores contribuem para este fato, um desses fatores é que os cooperativados ainda trabalham de forma artesanal e sem equipamentos e máquinas modernos que permitam aumentar sua produtividade. Outra dificuldade é ocasionada pela falta de condições para agregar novas famílias à cooperativa. Foi recorrente a afirmação de que muitas vezes eles preferem fazer uma venda direta para os atravessadores do que vincular sua produção a um contrato junto à usina. Essa questão cultural é uma característica que diferencia o Nordeste do Sul do país e contribui para dificuldade da Bahia, por exemplo, em aumentar sua produção de oleaginosa.

Foi identificado ainda preocupação da Diretoria da Cooperativa em conscientizar as famílias de agricultores locais sobre a possibilidade de aumento dos ganhos com a produção para os associados. Essa situação indica necessidade de assistência técnica não apenas para a produção da oleaginosa, mas também na formação das cooperativas enquanto administrador de um negócio com fins lucrativos. Esse tipo de comportamento está associado à cultura das famílias de agricultores, que não estão acostumadas a trabalhar sob regra de contrato.

Em relação à pesquisa junto às usinas de biodiesel instaladas no Estado da Bahia, apenas a PBio, localizada no município de Candeias, Bahia, participou do estudo. A pesquisa 
CASTRO, L. S. de; CARNEIRO, R. A. F. CONSEQUÊNCIAS do arcabouço regulatório do biodiesel brasileiro para as usinas produtoras: uma análise da situação da Bahia

não foi realizada na Oleoplan (antiga Vanguarda Biodiesel), localizada em Iraquara, pela dificuldade em se estabelecer contato com a unidade.

A PBio não permitiu uma pesquisa de campo, alegando que por segurança as plantas de biodiesel são fechadas para pesquisas externas. Entretanto, a empresa respondeu a um questionário aplicado e que contribuiu para elucidar algumas dúvidas identificadas no início da pesquisa. Uma delas está relacionada à aquisição da mamona como matéria prima para o biodiesel mesmo sendo a oleaginosa não indicada tecnicamente para o processo de transformação. $O$ fato de a empresa estar adquirindo esta oleaginosa indica que a contratualização das usinas junto às cooperativas não está relacionado apenas com condições de produção, mas, também, com a manutenção do Selo Combustível Social que é garantido para as empresas que adquirem matéria prima da agricultura familiar. Esse ponto é bastante controverso, pois abre espaço para questionamentos sobre o real motivo da aquisição de uma oleaginosa inapropriada, que onera a empresa elevando os seus custos a título de promover a inclusão social da agricultura familiar. Vale ressaltar, que tal prática ainda é um agravante para formação da cadeia de valor do biodiesel, pois essa oleaginosa não é utilizada para a produção de biodiesel e é destinada para outros mercados.

Ao ser questionada sobre em quais estados são adquiridas as oleaginosas, a PBio informou comprar matéria prima nos estados da Bahia, Goiás, Ceará, Maranhão, Pará, Rio de Janeiro e Tocantins, informando ainda que esses dados são recentes, entre os meses de janeiro a abril de 2015. Essa informação mostra que a agricultura familiar baiana não está atendendo a demanda das usinas no volume necessário e que a principal usina da Bahia está buscando em outros estados a matéria-prima necessária para sua produção.

A PBio informou ainda que adquire matéria prima oriunda da agricultura empresarial visando manter a regularidade da oferta, pela dificuldade que a agricultura familiar tem de cumprir os contratos. Isso sugere que o modelo de organização da produção no Nordeste, que fomenta a agricultura familiar como base de oferta de oleaginosas não funciona, uma vez que demonstra ser incapaz de atender a demanda das empresas de biodiesel. Porém, apesar de reconhecer que existe quebra de contrato por parte das cooperativas agrícolas a empresa informou não impor existir penalidade para elas, sob o argumento que elas prejudicariam a agricultura familiar.

A situação apresentada acima demonstra que a Bahia não possui as condições necessárias para sustentar sua produção de biodiesel, proporcionando para outros estados uma 
CASTRO, L. S. de; CARNEIRO, R. A. F. CONSEQUÊNCIAS do arcabouço regulatório do biodiesel brasileiro para as usinas produtoras: uma análise da situação da Bahia

vantagem competitiva no mercado. Toda essa limitação acontece por questões relacionadas a problemas diversos gerados pela falta de aprimoramento dos mecanismos regulatórios e de fomento do governo.

\section{CONCLUSÃO}

O presente trabalho apresentou a importância que o arcabouço regulatório do biodiesel brasileiro tem para formação da cadeia de valor do produto no país, procurando demonstrar que os mecanismos regulatórios aplicados ao biodiesel precisam ser revisados, levando em consideração as características regionais de cada estado. No caso da Bahia, por exemplo, verifica-se que o PNPB, e seus instrumentos regulatórios, não estão conseguindo promover o aumento da produção de matérias prima para a indústria do biodiesel e, consequentemente, um maior crescimento sócio econômico das famílias de agricultores familiares. Como consequência, as usinas de biodiesel do estado estão fechando, sendo que atualmente existem apenas duas em funcionamento, trabalhando com grande capacidade ociosa.

Apesar do interesse governamental em aumentar a produção do biodiesel, associada à inclusão social dos agricultores familiares como agentes participantes do processo, ainda é perceptível que no Estado da Bahia as cooperativas carecem de avanços, o que ocasiona grandes dificuldades na formação de uma cadeia de valor. Uma possível reformulação da regulação precisa levar em conta essa limitação.

Apesar de a Bahia possuir um clima favorável ao desenvolvimento de várias oleaginosas, em comparação com outras regiões, fica evidenciado que o estado perde em competitividade e eficiência, fundamentais para a atração e consolidação das usinas de produção de biodiesel. Diante disso, torna-se necessário que o Governo do Estado requalifique sua atuação junto às cooperativas e empresas vinculadas ao PNPB para que possa ser feito um estudo detalhado acerca dos problemas enfrentados na cadeia do biodiesel, apontando caminhos para corrigi-los.

Outra questão que ficou evidenciada na pesquisa é que o atual modelo de contratualização tem se mostrado ineficiente para a Bahia, pois tanto a agricultura familiar como as usinas têm sofrido para se manter no mercado do biodiesel. Não se pode ter um modelo de contrato que aumente os custos das empresas de biodiesel com exigências que 
CASTRO, L. S. de; CARNEIRO, R. A. F. CONSEQUÊNCIAS do arcabouço regulatório do biodiesel brasileiro para as usinas produtoras: uma análise da situação da Bahia

fogem ao seu objetivo final. Além disso, os contratos celebrados não possuem cláusulas que coíbam a quebra de contrato entre as partes e ainda que tivessem, estas seriam extremamente prejudiciais para agricultura familiar que não está estruturada na Bahia para sofrer qualquer tipo de punição.

O aumento das misturas do biodiesel no diesel comum demandará aumento na produção, principalmente da base agrícola, mas a garantia desse crescimento precisará estar alicerçada em fortes investimentos em pesquisas, novas tecnologias, infraestrutura e novas políticas de regulação.

A celebração de contratos entre as usinas de biodiesel e as cooperativas agrícolas precisa ser revista, passando a ser feita por meio de negociação entre usinas e cooperativas, em que sejam previstos, e aplicadas, as sanções (para ambas as partes) por quebra de cláusulas contratuais.

O Governo Estadual também deve promover encontros de cooperativas agrícolas para apresentar e debater formas de melhorar a inclusão das famílias no mercado de biodiesel.

Apesar desse trabalho identificar uma série de dificuldades existentes na Bahia para manter as usinas de biodiesel em funcionamento, também foi possível identificar que existem condições de melhor o desempenho estadual no cenário nacional. Esse crescimento, entretanto, somente será possível se houver uma melhor governança que vise unir forças entre a iniciativa privada, os centros de pesquisa, órgãos públicos, setor financeiro, entre outros, com a agricultura local, seja ela familiar ou empresarial, para discutir os principais problemas enfrentados no estado.

Outro aspecto importante é a necessidade de revisar a política para o biodiesel nos estados nordestinos, desenvolver mudanças nas regras aplicadas ao biodiesel produzido na região. Principalmente pelos agricultores familiares, para, dessa forma, podermos gerar ganhos para essa parcela da sociedade.

\title{
THE IMPORTANCE OF THE REGULATORY FRAMEWORK OF THE BRAZILIAN BIODIESEL FOR VALUE CHAIN CREATION IN THE SECTOR - AN ANALYSIS OF THE SITUATION OF BAHIA
}

\begin{abstract}
This article discusses the consequences that the regulatory framework of the National Program for Production and Use of Biodiesel (PNPB) has to the formation of a value chain in


CASTRO, L. S. de; CARNEIRO, R. A. F. CONSEQUÊNCIAS do arcabouço regulatório do biodiesel brasileiro para as usinas produtoras: uma análise da situação da Bahia

the production of biodiesel in the state of Bahia. For this was made a review of the main regulatory tools and promoting biodiesel in the country, using a research methodology based on literature review, agricultural field research and questionnaire in biodiesel plant and cooperatives located in the state of Bahia to primary data collection. This research has social relevance as it addresses a topic that is much discussed worldwide, which is the creation of renewable energy sources. This study analyzes the relation between the regulatory framework of biodiesel and its impact on the formation of the product value chain. The difficulties faced by the state of Bahia in the formation and consolidation of agents participating in the production of biodiesel have been addressed as well. It was noticed in the study that there are great difficulties to ensure the supply of the plants located in the state of Bahia with the oil generated in the region, due to problems related to the culture of cooperative, trouble management, technical deficiency and transport infrastructure. Thus, the need arises for further reflection and discussions if the regulatory policies are attending or not the state of Bahia in structuring a sustainable biodiesel market.

Keywords: Biodiesel. Organization of production. Regulation. Value chain. National program for production and use of biodiesel.

\section{REFERÊNCIAS}

ALVARENGA, M.; YOUNG, C. E. F. Produção de biodiesel no Brasil, inclusão social e ganhos ambientais. Rio de Janeiro, 2013. Disponível em: <http://www.ie.ufrj.br/ images/gema/Gema_Artigos/2013/Alvarenga_Young_2013_ELAEE_Biodiesel_no_Brasil.pd f>. Acesso em: 29 out. 2014.

BAHIA. Secretaria de Infraestrutura do Estado da Bahia - SEINFRA. Balanço energético da Bahia: 1997-2013. Salvador, 2014. Disponível em: < http://www.seinfra.ba.gov.br/ >. Acesso em: 1 jul. 2015.

BRAGA, C. F. G. V.; BRAGA, L. V. Desafios da energia no Brasil: panorama regulatório da produção e comercialização do biodiesel. Cad. EBAPE.BR, Rio de Janeiro, v. 10, n. 3, set. 2012. Disponível em: <http://www.scielo.br/scielo.php?script=sci_arttext\&pid=S16793951 2012000300016\&lng=pt\&nrm=iso $>$. Acesso em: 22 out. 2014.

BRASIL. Agência Nacional de Petróleo, Gás Natural e Biocombustíveis - ANP. Anuário estatístico. 2014. Disponível em: <http://www.anp.gov.br/?pg=66833>. Acesso em: 24 out. 2014.

Resolução no 31, de 4 de novembro de 2005. 2005. Disponível em: <http://www.mme.gov.br/programas/biodiesel/galerias/arquivos/legislacao/ResolucaoANPn3 1de2005Leilao.pdf >. Acesso em: 31 out. 2014. 
CASTRO, L. S. de; CARNEIRO, R. A. F. CONSEQUÊNCIAS do arcabouço regulatório do biodiesel brasileiro para as usinas produtoras: uma análise da situação da Bahia

Resolução no 41, de 24 de novembro de 2004. 2004. Disponível em: <http://www.mme.gov.br/programas/biodiesel/galerias/arquivos/legislacao/Resolucao_41.pdf >. Acesso em: 31 out. 2014.

Lei $n^{\circ} 11.097$, de 13 de Janeiro de 2005. Dispõe sobre a introdução do biodiesel na matriz energética brasileira; altera as Leis $\mathrm{n}^{\mathrm{os}}$ 9.478, de 6 de agosto de 1997, 9.847, de 26 de outubro de 1999 e 10.636, de 30 de dezembro de 2002; e dá outras providências. Diário Oficial [da] República Federativa do Brasil, Brasília, DF, 13 jan. 2005. Disponível em: <http://www.planalto.gov.br/ccivil_03/_ato2004-2006/2005/Lei/L11097.htm>. Acesso em: 10 set. 2014.

Ministério de Minas e Energia. Biodiesel: o novo combustível do Brasil. Brasília, DF, 2004. Disponível em: <http://www.mme.gov.br/programas/biodiesel/galerias/arquivos/ biodiesel/cartilha_biodiesel_portugues.pdf. Acesso: 29 out. 2014.

. Ministério de Minas e Energia. Biodiesel. Brasília, DF, [2014]. Disponível em: <http://www.mme. gov.br/programas/biodiesel/menu/programa/objetivos_diretrizes.html >. Acesso em: 15 dez. 2014.

Ministério do Desenvolvimento Agrário. Biodiesel. [2014]. Disponível em: <http://www.mda.gov.br>. Acesso em: 20 set. 2014.

CÉSAR, A. da S. Análise dos direcionadores de competitividade para a cadeia produtiva de Biodiesel: o caso da mamona. Dissertação (Mestrado em Engenharia de Produção)Universidade Federal de São Carlos, São Carlos, 2009.

CÉSAR, A. da S.; BONFIM, R. M.; BATALHA, M. O. A importância da confiança na relação entre produtores familiares de mamona e usinas de Biodiesel no Brasil. In: ENCONTRO NACIONAL DE ENGENHARIA DE PRODUÇÃO, 32., 2012. Bento Gonçalves, RS. Anais... Bento Gonçalves, RS, 2012.

CUNHA, M. L. da. Análise dos impactos de uma usina de biodiesel à luz dos objetivos e das diretrizes do Programa Nacional de Produção e Uso do Biodiesel. Brasília, DF: Câmara dos Deputados, 2010.

FERREIRA, J. E. R.; CARNEIRO, R. A. F. Infraestrutura logística: o elo que falta para a consolidação do ambiente de negócio das biomassas: o caso do biodiesel e do etanol. In: EXLER, R. B.; SAMPAIO, L. P.; TEIXEIRA, L. P. B. (Org.). Bioenergia: um diálogo renovável. Salvador: Vento Leste, 2013. v. 2.

GIL, A. C. Como elaborar projetos de pesquisa. 5. ed. São Paulo: Atlas, 2010. 
CASTRO, L. S. de; CARNEIRO, R. A. F. CONSEQUÊNCIAS do arcabouço regulatório do biodiesel brasileiro para as usinas produtoras: uma análise da situação da Bahia

MARTINS, L. O. S. Análise da viabilidade técnica e econômica da produção do biodiesel a partir do sebo bovino no estado da Bahia. Dissertação (Mestrado em Bioenergia)Faculdade de Tecnologia e Ciências de Salvador, Salvador, 2013.

PAULILLO, L. F.; MELLO, F. O. T.; VIAN, C. E. F. Análise da competitividade das cadeias de agroenergia no Brasil. In: BUAINAIN, A. M.; BATALHA, M. O. Análise da competitividade das cadeias agroindustriais brasileiras. São Carlos: DEP-UFSCAR/IEUNICAMP, 2006.

PECI, A. Reforma regulatória brasileira dos anos 90 à luz do modelo de Kleber Nascimento. Rev. adm. contemp., Curitiba , v. 11, n. 1, p. 11-30, mar. 200. Disponível em: $<$ http://www.scielo.br/scielo.php?script=sci_arttext\&pid=S1415-65552007000100002 $\& \operatorname{lng}=$ en $\& n r m=i s o>$. Acesso em: 30 jun. 2015.

PIZAIA, M. G. et al. A política regulatória do uso da água: estudo de caso para o Estado do Paraná. Cad. EBAPE.BR, Rio de Janeiro, v. 2, n. 3, p. 1-15, dez. 2004.

PORTER, M. E. Vantagem competitiva: criando e sustentando um desempenho superior. 26. ed. Rio de Janeiro: Campus, 1989.

QUINTELLA, C. M. et al. Cadeia do biodiesel da bancada à indústria: uma visão geral com prospecção de tarefas e oportunidades para P\&D\&I. Quím. Nova, São Paulo, v. 32, n. 3, p. 793-808, 2009. Disponível em: <http://www.scielo.br/scielo.php?script=sci_ arttext\&pid=S0100-40422009000300022\&lng=en\&nrm=iso>. Acesso em: 7 abr. 2015.

SILVA, M. S. Biodiesel, inclusão social e competitividade: diagnóstico, estratégias e proposições para a cadeia produtiva no estado da Bahia. 2015. $339 \mathrm{f}$. Tese (Doutorado em Energia e Ambiente) - Universidade Federal da Bahia, Salvador, 2015.

SOUZA, C. Políticas públicas: uma revisão da literatura. Sociologias, Porto Alegre, ano 8, n. 16, p. 20-45, jul./dez. 2006.

Recebido em: 17/03/2016

Aprovado em: 21/06/2016

Publicado em: 05/07/2016 